\title{
Effect of moderate exercise on renal changes and oxidative stress in ovariectomized rats with type 1 diabetes mellitus
}

\author{
Mayane Oliveira Rebouças da Silveira*, Liliany Souza de Brito \\ Amaral, Samira Itana de Souza, Halanna Rocha Ferraz, Jéssica \\ Alves Dias, Edilene Cândido Rocha, Fernanda de Abreu Silva, \\ Amélia Cristina Mendes de Magalhães and Telma de Jesus Soares
}

Multidisciplinary Institute of Health. Federal University of Bahia. Rua Rio de Contas, 58, Quadra 17, Lote 58. Vitória da Conquista-BA, Brazil (CEP 45029-094). *Email: mayane.or@hotmail.com.

\begin{abstract}
This study evaluated the aerobic exercise effects of moderate and progressive intensity on renal function and structure, and oxidative stress in ovariectomized rats with type 1 diabetes mellitus induced by streptozotocin (STZ). Eighteen Wistar rats were divided into 3 groups: OSC - ovariectomized and sedentary control rats; OSD - ovariectomized and sedentary diabetic rats; and OTD - ovariectomized and trained diabetic rats. After induction of diabetes, the OTD group was submitted to eight weeks of exercise. Twenty-four hours after the last training session urine samples were collected. Blood samples and kidneys were collected after euthanasia for renal function analysis, histology, morphometry and oxidative stress. Our results have shown a reduction of the weight gain, increase of kidney weight and postprandial glycemia in diabetic rats. However, exercise decreased glycosuria and prevented the proteinuria in OTD group rats. Focal segmental glomerulosclerosis (FSGS), juxtamedullary glomerular tuft area, tubulointerstitial lesions (TIL), brush border loss and tubular cell debridement were reduced in OTD rats. In addition, exercise training decreased urinary and plasma concentrations of thiobarbituric acid reactive substance (TBARS). Our results demonstrate the beneficial effect of progressive aerobic exercise on proteinuria, glycosuria, and renal structure in ovariectomized diabetic rats, which may be mediated in part by reduction of oxidative stress.
\end{abstract}

Keywords: Diabetes mellitus; Ovariectomy; Kidney; Exercise training.
Received

December 12, 2018

Accepted

July 14, 2019

Available online

July 15, 2019

Released

August 31, 2019

Full Text Article

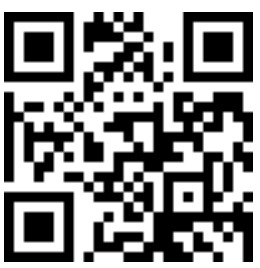

ORCID

D) 0000-0001-6849-8958 Mayane Oliveira Rebouças da Silveira

(D) 0000-0002-8434-0146 Liliany Souza de Brito Amaral

D 0000-0003-2922-764X Samira Itana de Souza

(1) 0000-0003-0865-9128 Halanna Rocha Ferraz 


\section{Introduction}

Chronic complications of diabetes mellitus (DM) mainly affect the cardiovascular and renal systems, being diabetic nephropathy the major cause of death among patients with type 1 diabetes mellitus (DM1) (Maric and Sullivan, 2008). Early diabetic nephropathy stages are characterized by change in renal function and structure, including glomerular hyperfiltration, mesangial expansion, adaptive renal hypertrophy, and microalbuminuria (Bangstad et al., 1993; Sharma and McGowan, 2000; Volpini et al., 2003). The loss of filtration barrier selectivity, as well as a reduction of the filtering surface result in dense proteinuria and marked decrease of glomerular filtration rate (GFR) with disease progression. (Trevisan et al., 1997). Renal pathophysiological processes mainly occur in the glomeruli, characterized by mesangial matrix expansion, glomerular basement membrane thickening, and lesion of the podocytes (Bangstad et al., 1993; Coimbra et al., 2000). However, the chronic hyperglycemic state also causes morphological changes in the renal tubules (Barutta et al., 2014).

Oxidative stress may be one mechanisms involved in the onset and progression of kidney disorders caused by diabetes (Palm et al., 2003). Hyperglycemia induces an increase in reactive oxygen species (ROS) and changes in renal structure, suggesting that this may be associated with the

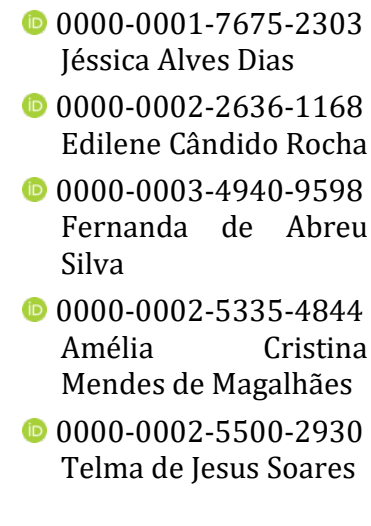

development of renal lesions (Mansouri et al., 2011; Punaro et al., 2014; Fernandes et al., 2016). Saleh et al. (2016) demonstrated that antioxidant treatment reduced urinary excretion of TBARS, endothelin 1 and glomerular superoxide production, in rats with DM1 induced by estreptozotocin (STZ).

Studies have shown an important influence of sex hormones on the incidence and progression of renal diseases, indicating the role of estrogen as a renoprotective factor, both in experimental animals and in women of reproductive age (Neugarten et al., 2000; Keck et al., 2007; Pérez-Torres et al., 2009. Ovariectomy can induce albuminuria, increased transforming growth factor beta (TGF- $\beta$ ) and glomerular structural proteins expression, severe glomerulosclerosis and tubulointerstitial fibrosis (Mankhey et al., 2005). On the other hand, some studies are controversial about the modulatory effect of female sex hormones on renal changes induced by diabetes, especially in the postmenopausal period.

Aerobic exercise has been associated to prevention of chronic diseases (Pedersen, 2006; Coelho and Burine, 2009), including diabetes mellitus (Bortolon et al., 2012; Huebschmann et al., 2015). The mechanisms of this protective effect on renal diseases, especially on diabetic renal disease, are not fully understood (Gusmão et al., 2003; Najas et al., 2009). However, evidences indicate that 
exercise improves glycemic control (Silva et al., 2012), bioavailability of nitric oxide (NO) (Rodrigues et al., 2011), inflammation (Agarwal et al., 2012), oxidative stress (Peeri et al., 2013), cellular apoptosis (Miyagi et al., 2014), in addition to beneficially modulating the Renin-Angiotensin-Aldosterone System (RAAS) (Ciampone et al., 2011).

In this perspective, since there are few studies investigating the relationship between diabetes and renal lesions, especially in conditions of decreased levels of ovarian hormones, in our study we aimed evaluate the effects exercise training of moderate and progressive intensity on the renal function and structure alterations and oxidative stress induced by diabetes mellitus in ovariectomized rats.

\section{Materials and methods}

\section{Animals}

Eighteen Wistar rats at 10 weeks of age and body weight around 180$200 \mathrm{~g}$ were maintained in light/dark cycle and temperature $23{ }^{\circ} \mathrm{C} \pm 3{ }^{\circ} \mathrm{C}$, with free access to water and food ad libitum. The animals were divided into three experimental groups with six animals in each group: OSC - ovariectomized sedentary control rats; OSD ovarectomized and sedentary diabetic rats; and OTD - ovariectomized and trained diabetic rats. This study was approved by the Ethics Committee in Animal Experimentation of the Federal University of Bahia - Multidisciplinary Institute of Health (Protocol No. 008/2013). All experimental procedures were conducted in accordance with the recommendations of the National Council for the Control of Animal Experimentation (CONCEA) in Brazil.

\section{Surgical procedure and induction of diabetes melittus \\ The rats were anesthetized with xylazine $(6 \mathrm{mg} / \mathrm{kg})$ and ketamine (40 mg/kg), and submitted bilateral ovariectomy surgery (Amaral et al.,}

2014). After seven days of surgical recovery, diabetes was induced by a single intravenous injection of STZ $(40 \mathrm{mg} / \mathrm{kg})$, diluted in $0.1 \mathrm{M}$ citrate buffer. Control rats were injected with equivalent amounts of citrate buffer. One week after the injection of STZ, the diabetes was confirmed by measuring blood glucose levels in a tail vein blood samples with Accu-Chek glucose strips (Roche, Mannheim, Germany). The animals with blood glucose levels higher than $250 \mathrm{mg} / \mathrm{dL}$ were considered diabetic (Amaral et al., 2016).

\section{Maximal running test and exercise training protocol}

The maximal running tests were performed at the beginning, at 4 weeks and at the end of the experiment with the objective of evaluating the physical capacity of the animals and/or adjusting the intensity of the exercise according to the method described by Amaral et al. (2016). Exercise training for the OTD group consisted of treadmill running at $0 \%$ inclination, five days per week, with a ten minutes volume in the first week, and increments of 10 minutes per week until the animal reached the maximal volume of $1 \mathrm{~h}$ in the end of the fourth week. Similarly, the intensity of the exercise was also progressively increased from $55-70 \%$ of the maximal capacity reached by the animal in the maximal running test, adding another 5\% each week (Souza et al., 2007; Rodrigues et al., 2011; Silva et al., 2012). One week after induction of diabetes, the OTD group was submitted training protocol over a period of 8 weeks (Figure 1).

\section{Body weight, uterine index and kidney weight}

The body weight gain of the animals was determined weekly and assessed by the delta weight (Zambom et al., 2009). After euthanasia, the uterus of the rats was removed and weighed for determination of the uterine index and verification of uterine atrophy. The kidneys were also removed, weighed and 
fixed for histological studies. The weight of the kidney was evaluated by the mean left and right kidney weight.

\section{Blood pressure, postprandial glycemia and glycosuria}

Blood pressure was measured at the end of each week, before the exercise sessions, by a programmable tail-cuff sphygmomanometer (LE 5001 ElectroSphygmomanometer - Panlab, Spain).
Due to the weakened state of the diabetic rats, it was not possible to perform the fasting glucose test. Therefore, the glycemic profile of rats was evaluated by postprandial glycemia with trunk blood collected after euthanasia. Both postprandial glycemia and glycosuria were determined by colorimetric method using an automated biochemical analyzer (Abbott Diagnostics C.4100 - SaintLaurent, Quebec, Canada).

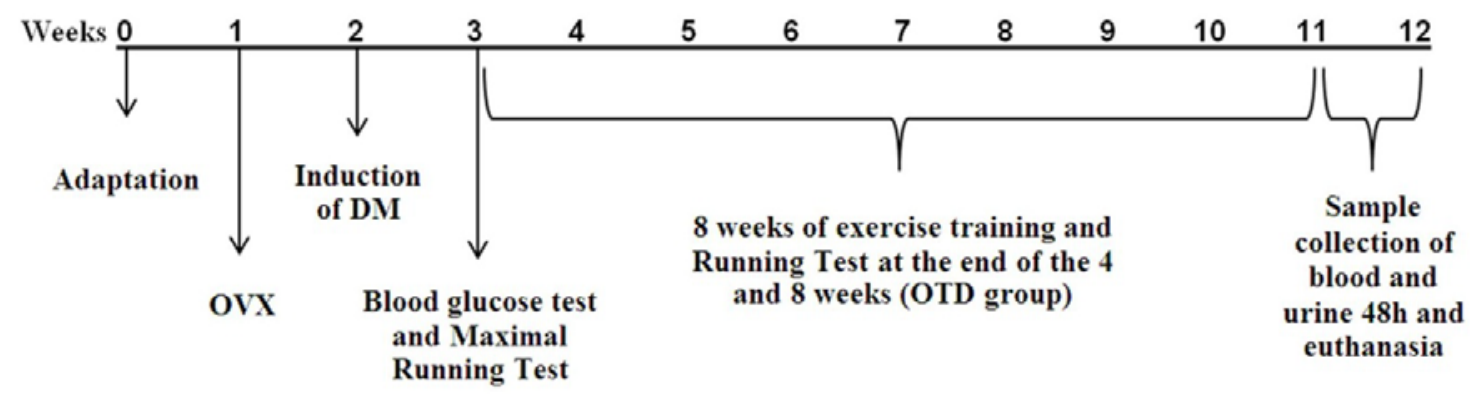

Figure 1. Experimental design. 0-1 (week), adaptation period on the treadmill and ovariectomy; 2-3 (weeks) induction of DM in the OSD and OTD groups; 3-11 (weeks), initiation of exercise training in the OTD group; $48 \mathrm{~h}$, sample collection of blood and urine $48 \mathrm{~h}$ after the last training session, and euthanasia.

\section{Renal function}

Forty-eight hours after the last training session, the animals were placed in metabolic cages for 24-hour urine collection. After euthanasia, blood samples were collected to quantify sodium, potassium and creatinine concentrations. Creatinine analysis in blood and urine samples was performed by the Jaffé method (Haugen, 1953). Glomerular filtration rate (GFR) was determined by creatinine Clearance. Sodium and potassium dosages were performed by flame photometry (Mod. 910, Analyser, São Paulo, Brazil) and the fractional excretion of these ions were calculated. Urinary flow was determined by total urine volume in 24 hours. Quantification of urinary protein was performed using the colorimetric method using the commercial kit Sensiprot (Labtest ${ }^{\circledR}, \mathrm{MG}$, Brazil).

\section{Renal Morphology}

After euthanasia, the kidneys samples from rats of all groups were fixed in methacarn solution (methanol $60 \%$, chloroform $30 \%$, and $10 \%$ acetic acid) and processed for paraffin embedding. Four- $\mu \mathrm{m}$ histological sections were stained with Periodic Acid Shift (PAS) for evaluation of the glomerulus and Hematoxylin and Eosin (HE) for evaluation of the tubulointerstitial compartment.

Glomerulosclerotic index (GSI)

Focal segmental glomerulosclerosis (FSGS) was determined by GSI 
through the optical microscopic analysis of 100 glomeruli. The FSGS was evidenced by increased mesangial matrix, obliteration and dilation of capillary lumina and it was graded according to Saito et al. (1987) on a scale of 0 to 4 (0 score, normal glomeruli; Score 1, sclera area up to 25\%; Score 2, sclerotic area of 25 to $50 \%$; Score 3, sclerotic area of 50 to $75 \%$; Score 4 , sclerotic area of $75 \%$ to $100 \%$. The GSI was calculated according to the formula:

$$
\mathrm{GSI}=(1 \times \mathrm{n} 1)+(2 \times \mathrm{n} 2)+(3 \times \mathrm{n} 3)+(4 \times \mathrm{n} 4) / \mathrm{nT}
$$

where

$\mathrm{n} 1$ represents the number of glomeruli with a score of 1 , $\mathrm{n} 2$ represents number of glomeruli with score 2 , n3 represents the number of glomeruli with score 3, n4 represents the number of glomeruli with score 4, and $\mathrm{nT}$ represents the total number of glomeruli evaluated.

\section{analysis \\ Glomerular morphometric}

The glomerular morphometric analysis was done by measuring the glomerular tuft area of 30 glomeruli of the cortical region and 20 of the juxtamedullary region of each animal. The capsular space was also analyzed by measurement of the renal corpuscle subtracted from the glomerular tuft area. The images were obtained by light microscopy captured by video camera connected to an image analyzer (Olympus BX51 - Japan) using the 40X objective. The area was delimited manually and determined by computerized morphometry using software.

\section{Tubulointerstitial lesions}

The evaluation of tubulointerstitial lesions (TIL) was performed in 30 cortical/animal fields characterized by tubular lumen dilatation, flattening, brush border loss, debridement and presence of hydropic degeneration. These changes were quantified by semiquantitative score, using score 0: no lesion; Score 0.5: small areas of discrete and focal lesions; Score 1 : lesion reaching an area $<10 \%$ of the cortex; Score 2: lesion reaching an area of $10 \%-25 \%$ : score 3 : lesion reaching an area of $25 \%-75 \%$ and score 4 : extensive and diffuse lesion reaching an area $>75 \%$ (Shih et al., 1988). Quantitative analysis was performed through of the percentage of each type of lesion per animal.

\section{Oxidative stress}

Plasma and urinary TBARS concentrations were determined by thiobarbituric acid assay (Ohkawa et al., 1979). The urinary TBARS was corrected by the $24 \mathrm{~h}$ urinary volume. The solution was read at a wavelength of $534 \mathrm{~nm}$ by spectrophotometry.

\section{Statistical analysis}

Statistical analysis was performed with the GraphPad Prism 6 program. The Kolmogorov-Smirnov test was performed to evaluate the normality of data distribution and the Bartlett test to analyze the homogeneity of the variances. Data were submitted to the Kruskal-Wallis nonparametric test with multiple comparisons by the Dunn test, and expressed as median and 25th and 75th percentile, or ANOVA One-way, followed by the Newman-Keuls multiple comparisons test, and expressed as mean \pm standard error of the mean (SEM). Pearson or Spearman tests were used to analyze the correlations. Statistical significance was defined as $\mathrm{P}<0.05$. 


\section{Results}

\section{Body weight, uterine index and kidney weight}

The diabetic rats demonstrated decrease of the body weight gain compared to control group $(\mathrm{p}<0.05)$ (Table 1). All rats showed reduction of uterine index, indicating atrophy of the uterus due to reduction in circulating levels of ovarian hormones (Table 1). The kidney weight was greater in the diabetic rats than the control group $(\mathrm{p}<0.001)$ (Table 1).

\section{Blood pressure, postprandial glycemia, and glycosuria}

Our results do not demonstrate significant changes in systolic, diastolic and mean blood pressure, as well as in heart rate. Postprandial glycemia was increased in the OSD $(\mathrm{p}<0.05)$ and OTD $(\mathrm{p}<0.01)$ groups than the control. The rats of the OSD $(\mathrm{p}<0.001)$ and OTD $(\mathrm{p}<0.01)$ groups presented increased glycosuria. However, exercise decreased glycosuria in the OTD rats $(\mathrm{p}<0.05)$ (Table 1).

Table 1. Delta Weight Data, Uterine Index, Kidney Weight, Glycemia, Glicosuria, Heart Rate, Systolic Blood Pressure, Diastolic Blood Pressure and Mean Arterial Pressure of ovariectomized sedentary control rats (OSC), ovariectomized sedentary diabetic rats (OSD) and ovariectomized trained diabetic rats (OTD).

\begin{tabular}{lccc}
\hline & OSC & OSD & OTD \\
\hline DW & $72.1(47.1 ; 78,8)$ & $7.9(-7.6 ; 30.9)^{*}$ & $1.2(-4.6 ; 8.4)^{*}$ \\
UI & $47.31(34.72 ; 138.1)$ & $57.01(47.26 ; 72.41)$ & $54.70(48.47 ; 197.2)$ \\
KW/BW & $0.34 \pm 0.01$ & $0.66 \pm 0.05^{* * *}$ & $0.56 \pm 0.2^{* * *}$ \\
PPG & $110.4(106.3 ; 119.4)$ & $674.6(578,6 ; 824)^{*}$ & $785(629.7 ; 985.6)^{* *}$ \\
U $_{\text {Glic }}$ & $1.52 \pm 0.30$ & $2019 \pm 237.2^{* * *}$ & $1288 \pm 329.6^{* * \#}$ \\
HR & $367.8 \pm 7.8$ & $353.9 \pm 28.8$ & $348.5 \pm 26.1$ \\
SBP & $126.2 \pm 2.6$ & $123.9 \pm 1.6$ & $131.3 \pm 5.9$ \\
DBP & $73.17 \pm 3.0$ & $70.47 \pm 1.3$ & $78.80 \pm 3.6$ \\
MAP & $90.56 \pm 2.6$ & $87.94 \pm 1.2$ & $95.40 \pm 4.1$ \\
\hline
\end{tabular}

Note: The data are reported as mean \pm SEM, or median and percentile 25 and 75 . DW, delta weight (g); UI, uterine index (mg/100g/BW); KW/BW, relative weight of kidneys (g/100g/BW); PPG, postprandial glycemia (mg/dL); UGlic., glicosuria $(\mathrm{mg} / 24 \mathrm{~h}) ; \mathrm{HR}$, heart rate (bpm); SBP, systolic blood pressure (mmHg); DBP, diastolic blood pressure $(\mathrm{mmHg})$; MAP, mean arterial pressure (mmHg). ${ }^{*} \mathrm{P}<0.05,{ }^{* *} \mathrm{P}<0.01$ and ${ }^{* * *} \mathrm{P}<0.001$ versus $\mathrm{OCS}$; ${ }^{*} \mathrm{P}<0.05$ versus 0 SD.

\section{Renal function}

All diabetic rats showed increases in urinary flow $(\mathrm{p}<0.01)$ and sodium and potassium excretion fractions $(p<0.05)$ compared to control rats (Table 2). Proteinuria was higher in the OSD group in relation to the control ( $p<0.001)$. Therefore, exercise prevented proteinuria in the OTD rats compared to the OSD group $(\mathrm{p}<0.05)$ (Table 2). There was no significant change in plasma creatinine concentration and GFR between the experimental groups.

\section{Renal histology and morphometry}

The diabetic rats of the OSD and OTD groups presented significant increases in the focal segmental glomerulosclerosis (FSGS) as determined by the glomerulosclerotic index (GSI), in relation to the control group ( $p<0.001)$. Exercise training reduced FSGS in OTD group rats compared to the OSD group $(p<0.05) \quad$ (Table 3). FSGS was characterized by dilation and obliteration of the glomerular capillaries, 
and increase of the mesangial matrix (Figure 2A, 2B, 2C). Correlations analysis showed that proteinuria was positively correlated to the GSI $(r=0.7112$, $\mathrm{p}<0.01$ ) (Figure 3C). The exercise prevented the increase of juxtamedullary glomerular tuft area in OTD group rats compared to the OSD group $(\mathrm{p}<0.01)$ (Table 3). An increase in Bowman's capsule space was observed for both cortical and juxtamedullary glomeruli only in the OSD rats compared to the control $(\mathrm{p}<0.05)$ (Table 3).

Table 2. Renal function data of ovariectomized sedentary control rats (OSC), ovariectomized sedentary diabetic rats (OSD) and ovariectomized trained diabetic rats (OTD).

\begin{tabular}{lccc}
\hline & OSC & OSD & OTD \\
\hline P $_{\text {Creat. }}$ & $0.3(0.3 ; 0.3)$ & $0.3(0.3 ; 0.4)$ & $0.4(0.2 ; 0.5)$ \\
GFR & $0.8 \pm 0.1$ & $0.6 \pm 0.1$ & $0.9 \pm 0.2$ \\
$\mathbf{U}_{\text {Flow }}$ & $4.33 \pm 0.92$ & $54.2 \pm 13.14^{* *}$ & $45.2 \pm 10.87^{* *}$ \\
FE $_{\mathrm{Na}+}$ & $0.38 \pm 0.03$ & $0.95 \pm 0.16^{*}$ & $1.15 \pm 0.25^{*}$ \\
FE $_{\mathrm{K}+}$ & $9.1(6.8 ; 9.3)$ & $31.0(26.7 ; 56.7)^{*}$ & $40.3(19.1 ; 45.8)^{*}$ \\
$\mathbf{U}_{\text {Prot. }}$ & $2.49 \pm 0.8$ & $29.35 \pm 6.15^{* * *}$ & $12.5 \pm 2.7^{\#}$ \\
\hline
\end{tabular}

Note: The data are reported as mean \pm SEM, or median and percentile 25 and 75. PCreat., plasma creatinine $(\mathrm{mg} / \mathrm{dL})$; GFR, glomerular filtration rate $(\mathrm{mL} / \mathrm{min} / 100 \mathrm{~g})$; UFlow, urinary flow $(\mu \mathrm{L} / \mathrm{min})$; $\mathrm{FENa}^{+}$, fractional excretion of sodium (\%); $\mathrm{FEK}^{+}$, fractional excretion of potassium (\%); UProt., proteinuria $(\mathrm{mg} / 24 \mathrm{~h}) .{ }^{*} \mathrm{P}<0.05,{ }^{* *} \mathrm{P}<0.01$ and ${ }^{* * *} \mathrm{P}<0.001$ versus $\mathrm{OCS}$; ${ }^{\#} \mathrm{P}<0.05$ versus OSD.

\section{OSC}

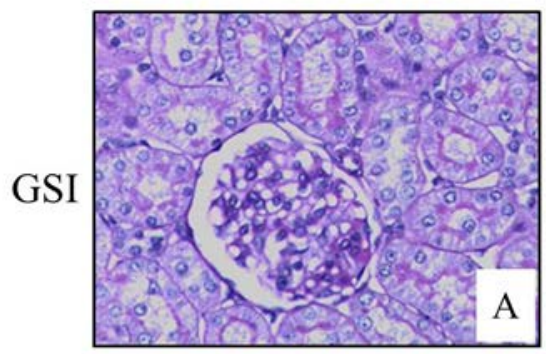

TIL

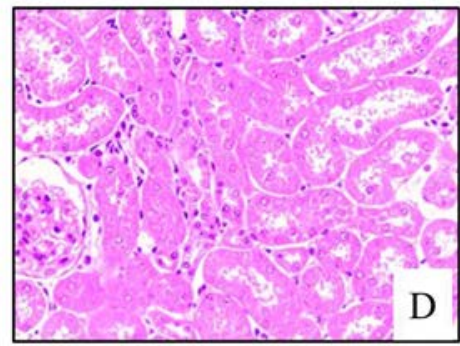

OSD
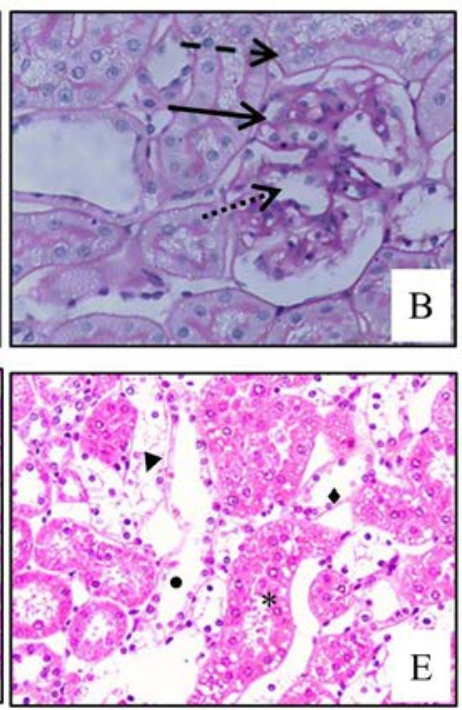

OTD
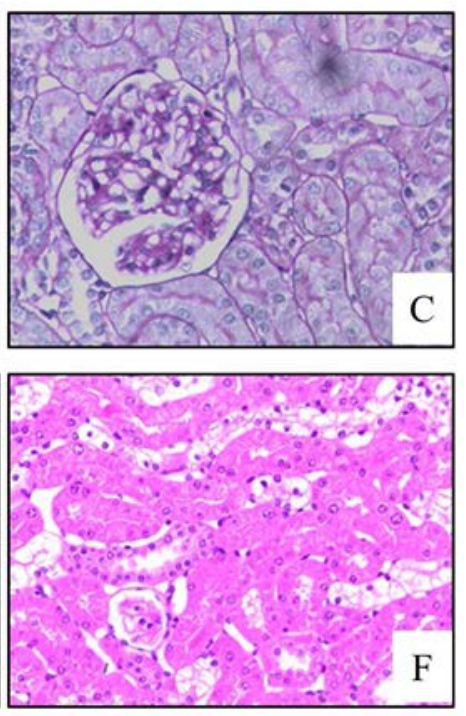

Figure 2. Representative photomicrographs of glomerular histological changes, PAS staining (A, B, C) and tubulointerstitial lesions, HE staining (D, E, F) of ovariectomized sedentary control rats (A, D), ovariectomized sedentary diabetic rats $(\mathrm{B}, \mathrm{E})$ and ovariectomized trained diabetic rats $(\mathrm{C}, \mathrm{F})$. Note in B dilation (arrow), segmental obliteration of capillary lumina (dotted arrow), increases in glomerular matrix (dashed arrow) and disorganization of glomerular architecture. Note in $\mathrm{C}$ that these changes have been reduced. Note in E hydropic degeneration (arrowhead), vacuolation (asterisk), brush border loss (lozenge) e debridement (circle). Note in $\mathrm{F}$ that these changes have been attenuated. Original magnification 200 in PAS and 400 in HE. 
The tubulointerstitial lesions were more intense in the renal cortex of the OSD $(p<0.01)$ and OTD $(p<0.05)$ rats compared to the control. In the OTD group, these lesions were attenuated by the exercise compared to the OSD group $(p<0.05)$ (Table 3, Figure 2D, 2E, 2F). The stratified analysis revealed a significant increase of the hydropic degeneration/vacuolation, the brush border loss, dilation/flattening, debridement and necrosis of the tubular cells in the OSD rats. The exercise reduced brush border loss and debridement of the tubular cells compared to the OSD group $(\mathrm{p}<0.05)$ (Table 3, Figure 2).

Table 3. Data on renal morphology and histology of ovariectomized sedentary control rats (OSC), ovariectomized sedentary diabetic rats (OSD) and ovariectomized trained diabetic rats (OTD)..

\begin{tabular}{lccc}
\hline & OSC & OSD & OTD \\
\hline GSI & $0.21(0.19 ; 0.25)$ & $0.96(0.86 ; 1.09)^{* * *}$ & $0.75(0.73 ; 0.97)^{* * * \#}$ \\
GTA $_{\mathbf{c}}$ & $3569 \pm 68.67$ & $4576 \pm 205.30^{* *}$ & $4440 \pm 173.0^{* *}$ \\
GTA $_{\text {jm }}$ & $3655 \pm 110.90$ & $5238 \pm 229.70^{* * *}$ & $4238 \pm 217.6^{\# \#}$ \\
CSA $_{\mathbf{c}}$ & $1209 \pm 90.39$ & $2304 \pm 463.6^{*}$ & $1430 \pm 205.6$ \\
CSA $_{\text {jm }}$ & $959.5(936.5 ; 1237)$ & $1880(1332 ; 2440)^{*}$ & $1183(892.8 ; 1686)$ \\
TIL & $0.75 \pm 0.11$ & $1.98 \pm 0.27^{* *}$ & $1.35 \pm 1.34^{* \#}$ \\
Hyd Deg/Vac & $14.4 \pm 2.8$ & $39.3 \pm 7.0^{*}$ & $28.3 \pm 6.1$ \\
BBL & $3.9 \pm 0.7$ & $11.1 \pm 2.4^{*}$ & $4.3 \pm 1.5^{\#}$ \\
Dil/Flat & $0.3 \pm 0.05$ & $4.5 \pm 1.0^{* *}$ & $3.3 \pm 0.8^{*}$ \\
Debridement & $2.4 \pm 0.6$ & $5.3 \pm 0.8^{*}$ & $2.5 \pm 0.8^{\#}$ \\
Necrosis & $0.2 \pm 0.1$ & $0.8 \pm 0.2^{* *}$ & $0.6 \pm 0.1^{*}$ \\
\hline
\end{tabular}

Note: The data are reported as mean \pm SEM, or median and percentile 25 and 75 . GI, glomerulosclerotic index (score); GTAc, cortical glomerular tuft area $\left(\mu \mathrm{m}^{2}\right)$; GTAjm, juxtamedular glomerular tuft area $\left(\mu \mathrm{m}^{2}\right)$; CSAc, capsular space area of the cortical glomeruli $\left(\mu \mathrm{m}^{2}\right)$; CSAjm, capsular space area of the juxtamedular glomeruli $\left(\mu \mathrm{m}^{2}\right)$; TIL, tubulointerstitial lesions (score); Hyd Deg/Vac, hydropic degeneration and vacuolation (\%); BBL, brush border loss (\%); Dil/Flat, dilation and flattening (\%); Debridement (\%); Necrosis (\%) . ${ }^{*} \mathrm{P}<0.05,{ }^{* *} \mathrm{P}<0.01$ and ${ }^{* * *} \mathrm{P}<0.001$ versus OSC; ${ }^{\mathrm{P}}<0.05$ and ${ }^{\# \#} \mathrm{P}<0.01$ versus $\mathrm{OSD}$.

\section{Plasma and urinary TBARS dosages}

The exercise reduced plasma TBARS concentrations in the OTD rats compared to the OSD group ( $p<0.05)$ (Figure 3A). The high concentrations of urinary TBARS in the OSD group were prevented by exercise in the OTD group $(p<0.05) \quad$ (Figure 3B). Positive correlation $(r=0.6408$ and $P<0.05)$ was observed between proteinuria and urinary TBARS levels (Figure 3D). 
$\mathbf{A}$

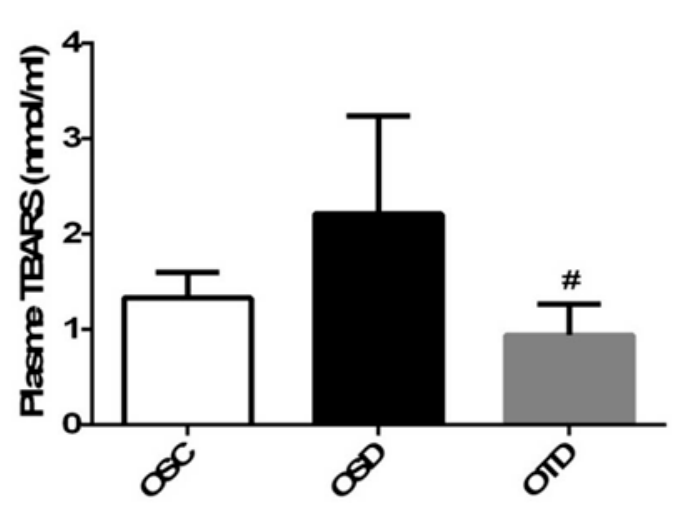

C

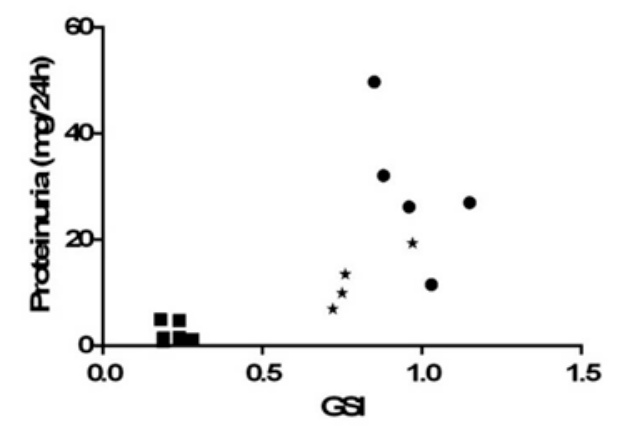

B

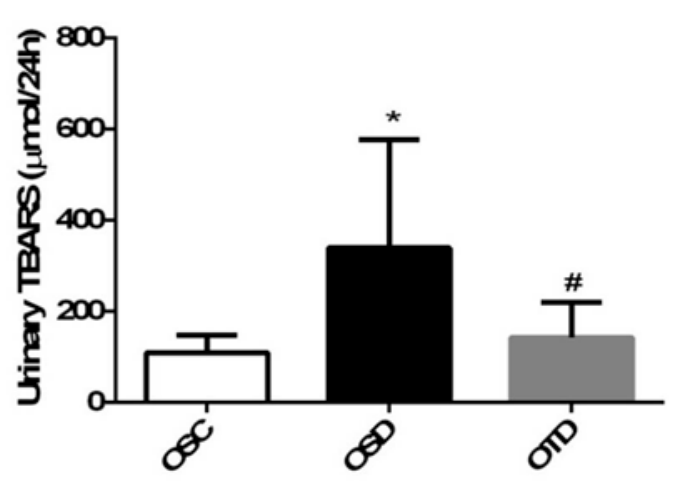

D

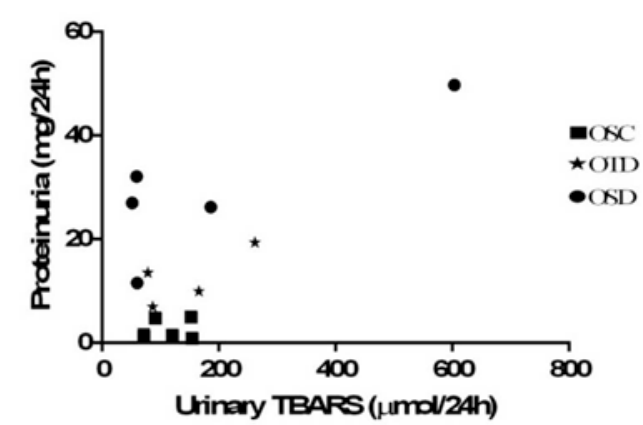

Figure 3. Plasma (A) and urinary (B) TBARS concentration of ovariectomized sedentary control rats (OSC), ovariectomized sedentary diabetic rats (OSD) and ovariectomized trained diabetic rats (OTD) ${ }^{*} \mathrm{P}<0.05$ versus OSC and ${ }^{\#} \mathrm{P}<0.05$ versus $\mathrm{OSD}$. Pearson's correlation of proteinuria versus GSI, $r=0.7112$ and $\mathrm{P}<0.01$ (C) and proteinuria versus urinary TBARS, $\mathrm{r}=0.6408$ and $\mathrm{P}<0.05$ (D).

\section{Discussion}

In this study, we analyzed the effect of exercise training of moderate and progressive intensity on renal function and structure changes and oxidative stress in ovariectomized rats with DM1 induced by STZ.

The efficacy of ovariectomy was demonstrated by the reduction in the volume and weight of the uterus in all ovariectomized rats demonstrating that estrogen deficiency induced gradual involution of the endometrium (Camargo et al., 2011). Ovariectomy may also induce weight gain in non-diabetic rats when compared to intact rats (Mankhey et al., 2005). However, Riazi et al. (2006) demonstrated that the association of ovariectomy and diabetes caused greater weight loss in diabetic rats induced by STZ. Our data also demonstrate a reduction in weight gain in diabetic ovariectomized rats without significant influence of exercise. Other studies have suggested that exercise improved metabolic capacity in STZ-induced diabetic female rats (Amaral et al., 2016) and exercised obese diabetic rats (Ito et al., 2015). Our data also show increased kidney weight in ovariectomized diabetic rats, which may be explained by renal 
hypertrophy characteristic of early diabetic nephropathy (Suarez et al., 2013). However, exercise did not reduce kidney weight. Amaral et al. (2016) also observed increased kidney weight in intact diabetic female rats, but this increase was attenuated by exercise training.

In our study, all diabetic rats showed increased postprandial glycemia. However, this increase was not associated with diet, since there was no difference in feed intake between the experimental groups. It has been shown that exercise reduces fasting glucose and insulin levels, improves glucose tolerance, and stimulates glucose uptake in ovariectomized diabetic Zucker rats (Bergeran et al., 2014). On the other hand, Furukawa et al. (2013) showed that the exercise improved body weight, blood pressure, renal function and morphology without, however, altering glycemia in type $2 \mathrm{DM}$. Although exercise is not always associated with glycemic control, locally, it has been shown that moderate exercise induces increased pancreatic beta cell mass and reduces the apoptosis of these cells (Choi et al., 2005). Exercise training reduced glycosuria in OTD group rats. Concentration of the GLUT1 transporter was reduced in STZ-induced diabetic mice (Machado, 1998). Exercise increases muscle blood flow, glucose uptake and insulin binding to its receptor (Pauli et al. 2009). Moderate exercise induces an increase in the number of GLUT 4 glucose transporters in the muscle (Ebersbach-Silva et al., 2013), which may induce reduced glycosuria.

Proteinuria is directly related to the progression of the renal lesion, being, therefore, an important marker of the renal function (Guimarães et al., 2007, Murussi et al., 2008). Our results showed elevated proteinuria in OSD rats. However, exercise training prevented the urinary excretion of proteins in OTD group rats. Increased proteinuria in diabetic animals may be associated with structural protein impairment and glomerular permeability triggered by hyperglycemia (Ito et al., 2015, Wang et al., 2015, Saleh et al., 2016). While beneficial effects of exercise were attributed to the reduction of hyperglycemia, proteinuria and albuminuria, improved bioavailability of nitric oxide and reduction of oxidative stress (Albright et al., 1995; Silva et al., 2012). Exercise did not attenuate increases in urinary flow and fractional excretion of sodium potassium induced by diabetes in the OTD group.

Although estrogen deficiency is associated with the development of glomerulosclerosis in postmenopausal women and in ovariectomized rats (Antus et al., 2003; Elliot et al., 2003; Chin et al., 2005), the condition of hyperglycemia and of diabetic nephropathy are also determinants for the development of glomerular lesions (Lagranha, 2007; Al-Trad et al., 2015). Our results evidenced increased focal segmental glomerulosclerosis in OSD rats and reduction of glomerular changes in the OTD group. Rodrigues et al. (2011) showed decreased constriction of glomerular capillaries, mesangial expansion, proteinuria, oxidative stress and improved bioavailability of NO in exercised DM1 rats. Amaral et al. (2016) also demonstrated that moderate exercise reduced glomerulosclerotic index, extracellular matrix protein and TGF- $\beta$ expression in STZ-induced diabetic female. In our study, there was also a positive correlation between proteinuria and GSI. These glomerular changes are responsible for the increase of the glomerular tuft area observed in the diabetic rats (Bangstad et al., 1993; Sharma and Mcgowan 2000; Volpini et al., 2003). Elliot et al. (2003), demonstrated that increased glomerular tuft and decreased vascular space were associated with ovariectomy. In our study, this increase was greater in the juxtamedullary glomeruli when compared to the cortical glomeruli. These juxtamedullary changes may be associated with podocyte lesions and 
aging by the greater intensity of desmin immunostaining in DM2 rats (Sofue et al., 2012). Exercise training reduced the of juxtamedullary glomerular tuft area in OTD group rats.

Tubulointerstitial lesions were more pronounced in the renal cortex of OSD rats, and this increase was attenuated by exercise in ODT rats. With the stratified analysis of these lesions, it was possible to observe greater hydropic degeneration/vacuolation, brush border loss, dilation/flattening, debridement and necrosis of tubular cells induced by diabetes. Vacuolar degeneration has also been demonstrated in sedentary diabetic rats (Rodrigues et al., 2011). Fernandes et al. (2016) observed tubular dilation and showed that changes in renal histology were induced by hyperglycemia due to the increase in reactive oxygen species. In our study, exercise reduced brush border loss and debridement of tubular cells. As the lesions are more prevalent in glomeruli, few studies evaluate the tubular changes correlating them to exercise and diabetes, mainly in the decrease of female sex hormones.

Our results demonstrate reduced plasma and urinary TBARS concentrations in ovariectomized trained diabetic rats. As demonstrated in our study, exercise reduced oxidative stress levels in diabetic rats and uninefrectomized diabetic rats (Fernandes et al., 2016). Rodrigues et al. (2011) evidenced decrease in plasma and urinary TBARS concentrations in rats with type 1 diabetes mellitus submitted to exercise. Exercise training attenuated the TBARS levels and improved renal superoxide dismutase activity and serum nitrite/nitrate, besides protecting against renal damage due to nitric oxide deficiency (Peeri et al., 2013). Our data also demonstrate a positive correlation between proteinuria and urinary TBARS. This is consistent with evidence that regular aerobic exercise, of moderate intensity, exerts protective effects on the diabetic kidney, preventing proteinuria and local oxidative stress both in animals (Albright et al., 1995; Silva et al., 2012) as in humans (Agarwal et al., 2012; Peeri et al., 2013).

\section{Conclusion}

Our data demonstrate that moderate aerobic exercise reduced glycosuria, proteinuria, focal segmental glomerulosclerosis, juxtamedullary glomerular tuft area, tubulointerstitial lesions, included decrease of brush border loss and debridement of tubular cells. In addition, exercise reduced the oxidative stress assessed by plasma and urinary TBARS. These benefits were observed without any pharmacological treatment, which proves the effectiveness of exercise as a therapeutic measure.

\section{Acknowledgments}

This work was supported by the Fundação de Amparo à Pesquisa do Estado da Bahia (FAPESB). We also thank to Cláudia Souza, Gabriela Pires, Israel Silveira e Monaliza Hipólito, students in our laboratory, for taking part in some aspects of these studies.

\section{Conflicts of interest}

Authors declare that they have no conflict of interests.

\section{References}

Agarwal, D.; Elks, C. M.; Reed, S. D.; Mariappan, N.; Majid, D. S. A.; Francis, J. Chronic exercise preserves renal structure and hemodynamics in spontaneously hypertensive rats. Antioxidants \& Redox Signaling, v. 16, no. 2, p. 139-152, 2012. https://doi.org/10.1089/ars.2011.3967

Albright, A. L.; Mahan, J. D.; Ward, K. M.; Sherman, W. M.; Roehrig K. L.; Kirby, T. E. Diabetic nephropathy in an aerobically trained rat model of diabetes. Medicine \& Science in Sports \& Exercise, v. 27, no.9, p. 1270-1277, 1995. 
Al-Trad, B.; Ashankyty, I. M.; Alaraj, M. Progesterone ameliorates diabetic nephropathy in streptozotocin-induced diabetic Rats. Diabetology \& Metabolic Syndrome, 7:97, 2015. https://doi.org/ 10.1186/s13098-015-0097-1

Amaral, L. S. B.; Silva, J. A.; Trindade, T. M.; Ribas, W. B. D.; Macedo, C. L.; Coimbra, T. M.; Belo, N. O.; Magalhães, A. C. M.; Soares, T. J. Renal changes in the early stages of dietinduced obesity in ovariectomized rats physiological. Physiological Research, v. 63, p. 723-732, 2014.

Amaral, L. S. B.; Silva, F. A.; Correia, V. B.; Andrade, C. E.; Dutra, B. A.; Oliveira, M. V.; Magalhães, A. C. D.; Volpini, R. A.; Seguro A. C.; Coimbra T.M.; Soares, T. D. J. Beneficial effects of previous exercise training on renal changes in streptozotocin-induced diabetic female rats. Experimental Biology and Medicine, v. 241, no. 4, p. 437-445, 2016. https://doi.org/10.1177/1535370215609696

Antus, B.; Hamar, P.; Kokeny, G.; Szollosi, Z.; Mucsi, I.; Nemes, Z.; Rosivall, L. Estradiol is nephroprotective in the rat remnant kidney. Nephrology Dialysis Transplantation, v. 18, no. $1, \quad$ p. 54-61, 2003. https://doi.org/10.1093/ndt/18.1.54

Bangstad, H. J.; Østerby, R.; Dahl-Jørgensen, K.; Berg, K. J.; Hartmann, A.; Nyberg, G.; Bjorn, S. F.; Hanssen, K. E. Early glomerulopathy is present in young, type 1 (Insulin-Dependent) diabetic patients with microalbuminuria. Diabetologia, v. 36, p. 523-529, 1993.

Barutta, F.; Bruno, G.; Grimaldi, S.; Gruden G. Inflammation in diabetic nephropathy: Moving toward clinical biomarkers and targets for treatment. Endocrine Rewiew, v. $48, \quad$ no. $3, \quad$ p. $730-742, \quad 2014$. https://doi.org/10.1007/s12020-014-0437-1

Bergeron, R.; Mentor, J. S.; Côté, I.; Ngo Sock, E. T.; Rabasa-Lhoret, R.; Lavoie, J. M. Loss of ovarian estrogens causes only mild deterioration of glucose homeostasis in female ZDF rats preventable by voluntary running exercise. Hormone Metabolism Research, v. 46, no. 11, p. 774-781, 2014. https://doi.org/10.1055/s-0034-1381980

Bortolon, J. R.; Silva Junior, A. J. A.; Murata, G. M.; Newsholme, P.; Curi R.; Pithon-Curi, T. C.; Hatanaka E. Persistence of inflammatory response to intense exercise in diabetic rats. Experimental Diabetes Research, v. 2012,
Article ID 213986, 2012. https://doi.org/ $10.1155 / 2012 / 213986$

Camargo, I. C. C.; Gênova, T. C.; Machado, M. C. P.; Frei, F.; Mesquita, S. F. P. Administração experimental de esteróide anabólico androgênico e álcool causa alterações histológicas e morfométricas nos ovários e útero de ratas adultas. Bioscience Journal, v. 27 , no. 4, p. 656-665, 2011.

Chin, M.; Isono, M.; Isshiki, K.; Araki, A.; Sugimoto, T.; Guo, B.; Sato, H.; Haneda, M.; Kashiwagi, A.; Koya, D. Estrogen and raloxifene, a selective estrogen receptor modulator, ameliorate renal damage in $\mathrm{db} / \mathrm{db}$ mice. American Journal of Pathology, v. 166 , no. 11 , p. 1629-1636, 2005. https://doi.org/10.1210/en.2004-1653

Choi, S. B.; Jang, J. S.; Park, S. Estrogen and exercise may enhance $\beta$-cell function and mass via insulin receptor substrate 2 induction in ovariectomized diabetic rats. Endocrinology, v. 146, p. 4786-4794, 2005. https://doi.org/10.1210/en.2004-1653

Ciampone, S.; Borges, R.; Lima, I. P. D.; Mesquita, F. F.; Cambiucci, E. C.; Gontijo J. A. R. Long-term exercise attenuates blood pressure responsiveness and modulates kidney angiotensin II signalling and urinary sodium excretion in SHR. Journal of ReninAngiotensin-Aldosterone System, v. 12, p. 394-403, 2011. https://doi.org/10.1177/ 1470320311408750

Coelho, C. F.; Burine, R. C. Atividade física para prevenção e tratamento das doenças crônicas não transmissíveis e da incapacidade funcional. Revista de Nutrição, v. 22, no. 6, p. 937-946, 2009. https://doi.org/10.1590/S1415-527320090 00600015

Coimbra, T. M.; Janssen, U.; Grone, H. J.; Ostendorf, T.; Kunter, U.; Schmidt, H.; Brabant, G.; Floege, J. Early events leading to renal injury in obese Zucker (fatty) rats with type II diabetes. Kidney International, v. 57, p. 167-182, 2000. https://doi.org/ 10.1046/j.1523-1755.2000.00836.x

Ebersbach-Silva, P.; Alves, T.; Fonseca, A. T.; Oliveira, M. A.; Machado, U. F.; Seraphim, P. M. Cigarette smoke exposure severely reduces peripheral insulin sensitivity without changing GLUT4 expression in oxidative muscle of Wistar rats. Arquivos Brasileiros de Endocrinologia \& Metabologia, v. 57, 
no. 1, p.19-26, 2013. https://doi.org/ 10.1590/S0004-27302013000100003

Elliot, S. J.; Karl, M.; Berho, M.; Potier, M.; Zheng, F.; Leclercq, B.; Striker, G. E.; Strieker, L. J. Estrogen deficiency accelerates progression of glomerulosclerosis in susceptible mice. American Journal of Pathology, v.162, no. 5, p. 1441-1448, 2003. https://doi.org/10.1016/S0002-9440(10) 64277-0

Fernandes, S. M.; Cordeiro, P. M.; Watanabe, M.; Fonseca, C. D.; Vattimo, M. F. F. The role of oxidative stress in streptozotocin-induced diabetic nephropathy in rats. Archives of Endocrinology and Metabolism, v, 60, p. 443-449, 2016.

Furukawa, M.; Gohda, T.; Tanimoto, M.; Tomino Y. Pathogenesis and novel treatment from the mouse model oftype 2 diabetic nephropathy. The Scientific World Journal, v. 2013, Article ID 928197, 2013. https://doi.org/10.1155/2013/928197

Guimarães, J.; Bastos, M.; Melo, M.; Carvalheiro, M. Nefropatia diabética: taxa de Filtração Glomerular Calculada e Estimada. Acta Medica Portuguesa, v. 20, no. 2, p. 145150, 2007.

Gusmão, L.; Galvão, J.; Possante M. A resposta do rim ao esforço físico. Revista Portuguesa de Nefrologia e Hipertensão, v. 17, no. 1, p. 73-80, 2003.

Haugen, H. N. The determination of "endogenous creatinine" in plasma and urine. Scandinavian Journal of Clinical and Laboratory Investigation, v. 5, no. 1, p. 4857, 1953. https://doi.org/10.3109/003655 15309093511

Huebschmann, A. G.; Kohrt, W. M., Herlache, L.; Wolfe, P.; Daugherty, S.; Reusch, J. E. B.; Bauer, T. A.; Regensteiner, J. G. Type 2 diabetes exaggerates exercise effort and impairs exercise performance in older women. BMJ Open Diabetes Research \& Care, v. 3, no 1, e000124, 2015. https://doi.org/10.1136/bmjdrc-2015000124

Ito, D.; Cao, P.; Kakihana, T.; Sato, E.; Suda, C.; Muroya, Y.; Ogawa, Y.; Hu, G.; Ishii, T.; Ito, O.; Kohzuki, M.; Kiyomoto, H. Chronic running exercise alleviates early progression of nephropathy with upregulation of nitric oxide synthases and suppression of glycation in Zucker diabetic rats. PLoS ONE, v. 10, no. 9, e0138037, 2015. https://doi.org/ 10.1371/journal.pone.0138037

Keck, M.; Romero-Aleshire, M. J.; Cai, Q.; Hoyer, P. B.; Brooks, H. L. Hormonal status affects the progression of STZ-induced diabetes and diabetic renal damage in the VCD mouse model of menopause. American Journal of Physiology-Renal Physiology, v. 293, no. 1, p. 193-199, 2007. https://doi.org/10.1152/ajprenal.00022.2007

Lagranha, C. J.; Fiorino, P.; Casarini, D. E.; Schaan, B. D.; Irigoyen, M. C. Bases moleculares da glomerulopatia diabética. Arquivos Brasileiros de Endocrinologia \& Metabologia, v. 51, p.901-912, 2007. https://doi.org/10.1590/S0004-27302007 000600003

Machado, U. F. Transportadores de glicose Arquivos Brasileiros de Endocrinologia \& Metabologia, $\quad$ v. 42, p. 413-421, 1998. https://doi.org/10.1590/ S000427301998000600003

Mankhey, R. W.; Bhatti, F.; Maric, C. 17 $\beta$ estradiol replacement improves renal function and pathology associated with diabetic nephropathy. American Journal of Physiology-Renal Physiology, v. 288, no. 2, p. F399-F405, 2005. https://doi.org/ 10.1152/ajprenal.00195.2004

Mansouri, E.; Panahi, M.; Ghaffari, M. A.; Ghorbani, A. Effects of grape seed proanthocyanidin extract on oxidative stress induced by diabetes in rat kidney. Iranian Biomedical Journal, v. 15, no. 3, p. 100-106, 2011.

Maric, C.; Sullivan, M. D. S. Estrogens and the diabetic kidney. Gender Medicine, v. 5, Suppl. 1, p.S103-S113, 2008. https://doi.org/10.1016/j.genm.2008.03.010

Miyagi, M. Y. S.; Seelaender, M.; Castoldi, A.; Almeida, D. C.; Bacurau, A. V. N.; AndradeOliveira, V.; Enjiu, L. M.; Pisciottano, M.; Hayashida, C. Y.; Hiyane, M. I.; Brum, P. C.; Camara, N. O. S.; Amano, M. T. Long-term aerobic exercise protects against cisplatininduced nephrotoxicity by modulating the expression of IL-6 and HO-1. PLoS ONE, v. 9, no. 10, e108543, 2014. https://doi.org/ 10.1371/journal.pone.0108543

Murussi, M.; Murussi, N.; Campagnolo, N.; Silveiro, S. P. Detecção precoce da nefropatia diabética. Arquivos Brasileiros de Endocrinologia \& Metabologia, v. 52, no. 3, 
p. 442-451, 2008. https://doi.org/10.1590/ S0004-27302008000300004

Najas, C. S.; Pissulin, F. D. M.; Pacagnelli, F. L.; Betônico, G. N.; Almeida, I. C.; Neder, J. A. Segurança e eficácia do treinamento físico na insuficiência renal crônica. Revista Brasileira de Medicina do Esporte, v. 15, no. 5, p. 384-388, 2009. https://doi.org/ 10.1590/S1517-86922009000600013

Neugarten, J.; Acharya, A.; Silbiger, S. R. Effect of gender on the progression of nondiabetic renal disease a meta-analysis. Journal of the American Society of Nephrology, v. 11, no. 2, p. 319-329, 2000.

Ohkawa, H.; Ohishi, N.; Yagi, K. Assay for lipid peroxides in animal tissues by thiobarbituric acid reaction. Analytical Biochemistry, v. 95, no. 2, p. 351-358, 1979. https://doi.org/10.1016/0003-2697(79) 90738-3

Palm, F.; Cederberg, J.; Hansell, P.; Liss, P.; Carlsson, P. O. Reactive oxygen species cause diabetes-induced decrease in renal oxygen tension. Diabetologia, v. 46 , no. 8, p. 11531160, 2003. https://doi.org/10.1007/ s00125-003-1155-z

Pauli, J. R.; Cintra, D. E.; Souza C. T.; Ropelle, E. R. Novos mecanismos pelos quais o exercício físico melhora a resistência à insulina no músculo esquelético. Arquivos Brasileiros de Endocrinologia \& Metabologia, v. 53, no. 4, p. 399-408, 2009. https://doi.org/10.1590/S0004-2730200 9000400003

Pedersen, B. K. The anti-inflammatory effect of exercise: Its role in diabetes and cardiovascular disease control. Essays in Biochemistry, v. 42, p. 105-117, 2006. https://doi.org/10.1042/bse0420105

Peeri, M.; Habibian, M.; Azarbayjani, M. A.; Hedayati, M. Protective effect of aerobic exercise against L-NAME induced kidney damage in rats. Archives of Industrial Hygiene and Toxicology, v. 64, p. 229-235, 2013. https://doi.org/10.2478/10004-125464-2013-2260

Pérez-Torres, I.; Roque, P.; Hafidi, M. E.; Diaz, E.; Baños, G. Association of renal damage and oxidative stress in a rat model of metabolic syndrome. Influence of gender. Free Radical Research, v. 43, no. 8, p. 761-771, 2009. https://doi.org/10.1080/107157609030452 96
Punaro, G. R.; Maciel, F. R.; Rodrigues, A. M.; Rogero, M. M.; Bogsan, C. S. B.; Oliveira, M. N.; Ihara, S. S. M.; Araujo, S. R. R.; Sanches, T. R. C.; Andrade, L. C.; Higa, E. M. S. Kefir administration reduced progression of renal injury in STZ-diabetic rats by lowering oxidative stress. Nitric Oxide, v. 37, p. 53-60, 2014. https://doi.org/10.1016/j.niox.2013. 12.012

Riazi, S.; Maric, C.; Ecelbarger, C. A. 17- $\beta$ Estradiol attenuates streptozotocin-induced diabetes and regulates the expression of renal sodium transporters. Kidney International, v. 69, no. 3, p. 471-480, 2006. https://doi.org/10.1038/sj.ki.5000140

Rodrigues, A. M.; Bergamaschi, C. T.; Araújo, R. C.; Mouro, M. G. Effects of training and nitric oxide on diabetic nephropathy progression in type I diabetic rats. Experimental Biology and Medicine, v. 236, no. 10 , p. $1180-1187,2011$. https://doi.org/10.1258\%2Febm.2011.0110 05

Saito, T.; Sumithran, E.; Glasgow, E. F.; Atkins, R. C. The enhancement of aminonucleoside nephrosis by the coadministration of protamine. Kidney International, v. 32, p. 691-699, 1987.

Saleh, M. A.; Miguel, C. D.; Stevens, D. I.; Carmines, P. K.; Pollock, D. M.; Pollock, J. S. Free radical scavenging decreases endothelin-1 excretion and glomerular albumin permeability during type 1 diabetes. Physiological Reports, v. 4, n. 4, e13055, 2016. https://doi.org/10.14814/phy2.13055

Sharma, K.; McGowan, T. A. TGF- $\beta$ in diabetic kidney disease: Role of novel signaling pathways. Cytokine \& Growth Factor Reviews, v. 11, no. $1 / 2$, p. 115-123, 2000. https://doi.org/10.1016/S1359-6101(99) 00035-0

Shih, W.; Hines, W. H.; Neilson E. G. Effects of cyclosporin A on the development of imunemediated interstitial nephritis. Kidney International, v. 33, no. 6, p. 1113-1118, 1988. https://doi.org/10.1038/ki.1988.119

Silva, K. A. S.; Luiz, R. S.; Rampaso, R. R.; Abreu, N. P.; Moreira, E. D.; Mostarda, C. T.; Angelis, K. D.; Teixeira, V. P. C.; Irigoyen, M. C.; Schor, N. Previous exercise training has a beneficial effect on renal and cardiovascular function in a model of diabetes. PLoS ONE, 
v. 7, no. 11, e48826, 2012. https://doi.org/ 10.1371/journal.pone.0048826

Sofue, T.; Kiyomoto, H.; Kobori, H.; Urushihara, M.; Nishijima, Y.; Kaifu, K.; Hara, T.; Matsumoto, S.; Ichimura, A.; Ohsaki, H.; Hitomi, H.; Kawachi, H.; Hayden, M. R.; Whaley-Connell, A.; Sowers, J. R.; Ito, S.; Kohno, M.; Nishiyama, A. Early treatment with Olmesartan prevents juxtamedullary glomerular podocyte injury and the onset of microalbuminuria in type 2 diabetic rats. American Journal of Hypertension, v. 25, no. 5, p. 604-611, 2012. https://doi.org/ 10.1038/ajh.2012.1

Souza, S. B. C.; Flues, K.; Paulini, J.; Mostarda, C.; Rodrigues, B.; Souza, L. E.; Irigoyen, M. C.; Angelis, K. D. Role of exercise training in cardiovascular autonomic dysfunction and mortality in diabetic ovariectomized rats. Hypertension, v. 50, no. 4, p. 786-791, 2007. https://doi.org/10.1161/HYPERTENSIONAH A.107.095000

Suarez, M. L. G.; Thomas, D. B.; Barisoni, L.; Fornoni, A. Diabetic nephropathy: Is it time yet for routine kidney biopsy? World Journal Diabetes, v. 4, no. 6, p. 245-255, 2013. https://doi.org/10.4239/wjd.v4.i6.245
Trevisan, R.; Barnes, D. J.; Viberti, G. Pathogenesis of diabetic nephropathy. In: Pickup, J. C.; Williams, J. Text book of diabetes. 2. ed. Oxford: Blackwell Science, 1997.

Volpini, R. A.; Silva, C. G. A.; Costa, R. S.; Coimbra, T. M. Effect of enalapril and losartan on the events that precede diabetic nephropathy in rats. Diabetes/Metabolism Research and Reviews, v. 19, p. 43-51, 2003.

Wang, J. H.; Ren, K.; Sun, W. G.; Zhao, L.; Zhong, H. S.; Xu, K. Effects of iodinated contrast agents on renal oxygenation level determined by blood oxygenation level dependent magnetic resonance imaging in rabbit models of type 1and type 2 diabetic nephropathy. BMC Nephrology, 15:140, 2014. https://doi.org/10.1186/1471-236915-140

Zambon, L.; Duarte, F. O.; Freitas, L. F.; Scarmagnani, F. R. R.; Dâmaso, A.; Duarte, A. C. G. O.; Sene-Fiorese, M. Efeitos de dois tipos de treinamento de natação sobre a adiposidade e o perfil lipídico de ratos obesos exógenos. Revista de Nutrição, v. 22, no. 5, p. 707-715, 2009. https://doi.org/10.1590/ S1415-52732009000500011

License information: This is an open-access article distributed under the terms of the Creative Commons Attribution License, which permits unrestricted use, distribution, and reproduction in any medium, provided the original work is properly cited. 